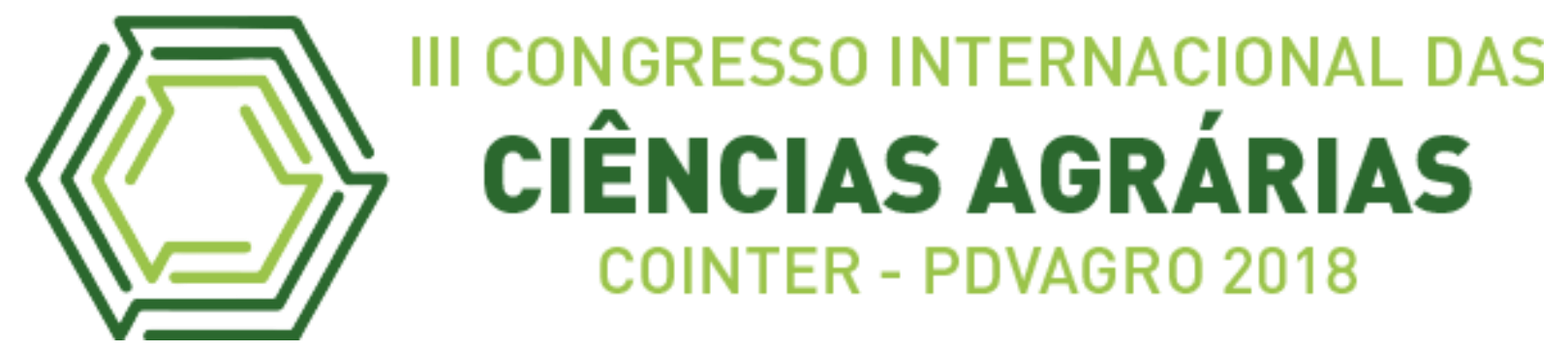

\title{
TOXICIDADE DE DIFERENTES EXTRATOS VEGETAIS PARA CONTROLE DE INSETOS-PRAGA NO FEIJÃO CAUPI (Vigna unguiculata (L.) Walp.)
}

\section{TOXICITY OF DIFFERENT VEGETABLE EXTRACTS FOR INSECT-PRAGUE CONTROL IN CAUPI BEANS (Vigna unguiculata (L.) Walp.) \\ Apresentação: Pôster}

\author{
Loirilene Rodrigues Carria ${ }^{1}$; Sâmila Marla Sales de Almeida ${ }^{2}$; Antonia Santos \\ Rodrigues ${ }^{3}$; Graziela Pereira dos Santos ${ }^{4}$; Glayde Maria Carvalho Veras ${ }^{5}$ \\ DOI: https://doi.org/10.31692/2526-7701.IIICOINTERPDVAGRO.2018.00679
}

\section{Introdução}

Com origem na África, o feijão-caupi (Vigna unguiculata L Walp.) é cultivado nas regiões Norte, Nordeste e Centro-Oeste (FREIRE FILHO et al., 2011). O feijão-caupi é rico em proteína e ferro e constitui a base da alimentação da população mais carente, junto com o arroz. Seu cultivo é feito principalmente por pequenos e médios agricultores com pouca tecnologia o que influencia na sua baixa produtividade (ALMEIDA et al., 2010).

Dentre os fatores que contribuem para a sua baixa produtividade estão as pragas, que quando não controladas, influenciam na diminuição da sua produção e rendimento. Os insetos que causam danos potenciais a planta surgem de acordo com cada fase de desenvolvimento da cultura (EMBRAPA, 2011) e dentre eles pode-se destacar a paquinha (Neocurtilla hexadactyla), a broca-do-colo ou lagarta-elasmo (Elasmopalpus lignosellus), a vaquinha com destaque para as espécies Diabrotica speciosa e Cerotoma arcuatus, a cigarrinha-verde (Empoasca sp), os pulgões da espécie Aphis craccivora; Aphis gossypii e Aphis faba, a Mosca-branca (Bemisia tabaci biótipo B), os percevejos das espécies Crinocerus sanctus;

\footnotetext{
${ }^{1}$ Bacharelado em Agronomia, Instituto Federal de Educação, Ciência e Tecnologia do Maranhão, IFMA, Campus Codó, E-mail: loirycarria@gmail.com

${ }^{2}$ Bacharelado em Agronomia, Instituto Federal de Educação, Ciência e Tecnologia do Maranhão, IFMA, Campus Codó, E-mail: samilamarla@hotmail.com

${ }^{3}$ Bacharelado em Agronomia, Instituto Federal de Educação, Ciência e Tecnologia do Maranhão, IFMA, Campus Codó, E-mail: antoniafirmino.ar@gmail.com

${ }^{4}$ Técnico em Agropecuária, Instituto Federal de Educação, Ciência e Tecnologia do Maranhão, IFMA, Campus Codó, E-mail: grazielasantos944@gmail.com

${ }^{5}$ Médica Veterinária, Mestre em Ciência Animal, professora do ensino técnico e superior, Instituto Federal de Educação, Ciência e Tecnologia do Maranhão, IFMA, Campus Codó, E-mail: glaydeveras@ifma.edu.br
} 
Piezodorus guildinii e Nezara viridula, além de outros, que provocam danos diversos à cultura (GALLO et al., 2002).

Para evitar esses prejuízos o uso de agroquímicos é a principal prática adotada para o controle de praga pelos agricultores do feijão-caupi (PONTES, 2005). Porém, o uso desregrado de inseticidas químicos tem gerado grandes impactos ambientais e à saúde humana. Devido a isto, uma alternativa para controle de insetos-pragas, são os extratos vegetais, por possuírem características como a sua rápida degradação, baixa toxicidade tanto para os vegetais quanto para quem os manipula, baixo custo, fácil manuseio e eficiência no controle de pragas (RABELO E BLEICHER, 2014).

Levando-se em consideração esses aspectos, o presente estudo teve como objetivo avaliar a eficiência de diferentes extratos vegetais no controle de insetos-praga na cultura do feijão-caupi.

\section{Fundamentação Teórica}

O feijão-caupi, também é conhecido popularmente, como feijão-macassar, feijão-decorda, fradinho, além de outros nomes (FREIRE FILHO et al, 2011). A cultura apresenta ciclo curto, baixa exigência hídrica e rusticidade, além de fixar nitrogênio no solo (FBN). Pelo seu valor nutritivo, é cultivado principalmente para a produção de grãos, secos ou verdes, para o consumo humano, in natura, na forma de conserva ou desidratado. Além disso, o caupi também é utilizado como forragem verde, feno, ensilagem, farinha para alimentação animal e, ainda, como adubação verde e proteção do solo (ANDRADE JÚNIOR et al., 2002).

A cultura vem conquistando espaço e ganhando atenção para a criação de novas cultivares com maior adaptabilidade ao tipo de solo, condições climáticas e resistência a pragas e doenças (EMBRAPA, 2011).

Para o controle de pragas na cultura, o controle químico é o mais utilizado (PONTES, 2005). Como alternativa, o uso de extratos naturais de plantas que sejam específicos, biodegradáveis, de fácil aquisição e de custo relativamente baixo, quando comparado aos inseticidas convencionais.

Segundo Sousa (2017), os óleos podem ser utilizados para o controle de pulgão-preto no feijão-caupi, sendo que o óleo essencial de L. lasiocalycina e o de L. origanoides os mais tóxicos, matando mais de 50\% dos indivíduos. Silva et al. (2011), constataram que o óleo de nim é eficiente no controle do pulgão, da mosca branca, da cigarrinha verde e do manhoso, 
mostrando ineficiência apenas no controle da vaquinha (Cerotoma arcuatus).

Alécio (2007), mostra em seu estudo que o extrato de timbó (Derris amazônica) é tóxico para vaquinha (Cerotoma arcuatus) e inibe a alimentação dos insetos, sendo a intoxicação por ingestão de folhas tratadas a via mais efetiva.

\section{Metodologia}

O experimento foi conduzido entre os meses de abril e julho de 2018, no campo experimental do Instituto Federal de Educação Ciência e Tecnologia do Maranhão (IFMA Campus - Codó). Região cujas características climáticas apresentam precipitação média de 800 a $1.200 \mathrm{~mm}$ anuais e temperaturas médias oscilando entre $32^{\circ} \mathrm{C}$ a $38^{\circ} \mathrm{C}$ e umidade relativa do ar em torno de $90 \%$ (BARROS, et al. 2011).

A pesquisa foi feita com a cultura do feijão-caupi, a cultivar utilizada foi a BRS Guariba, semeadas em garrafas PET's cortadas ao meio com substrato oriundo de esterco bovino. Em cada garrafa foi plantado 3 sementes de feijão caupi e realizado o desbaste deixando apenas uma planta por garrafa.

Os tratamentos utilizados, foram: T1: extrato da folha de nim (30\%); T2: fumo (30\%); T3: Pimenta Gota (30\%); T4: sabão de coco (30\%); T5: água destilada (testemunha). Foram feitas 3 aplicações, a primeira aos 10 DAE, a segunda aos 20 DAE e a terceira feita na fase de florescimento, utilizando bombinhas de $350 \mathrm{~mL}$ para aplicar a solução preparada de cada tratamento, sendo feitas 5 borrifadas por planta para boa uniformidade de aplicação. Cada tratamento foi observado dois dias após cada aplicação, para constar se houve: presença de inimigos naturais, presença de pragas (vivas e mortas), injúrias causadas a planta (pelo tratamento utilizado) e tipo de injúria causada por praga (desfolha).

O delineamento foi composto por 5 tratamentos com 4 repetições cada, totalizando 20 unidades amostrais, sendo que, cada unidade amostral possuiu 14 plantas e o número total de plantas de todos os tratamentos foi de 280 plantas.

\section{Resultados e Discussões}

Os insetos pragas encontrados foram a vaquinha Cerotoma arcuatus (Fig. 1A), que em sua fase adulta causa o desfolhamento da cultura, e o percevejo vermelho Crinocerus sanctus (Fig. 1B), que causa sérios prejuízos a planta em sua fase vegetativa ao sugar seus ramos. 
$\mathrm{O}$ ataque de vaquinha (Cerotoma arcuatus) foi severo em todos os tratamentos. As injúrias causadas, foram perfurações no limbo foliar, reduzindo a área fotossintética da planta (Fig. 1C).

O T2 (fumo- 30\%) em relação aos demais tratamentos utilizados, teve efeito na redução do ataque de vaquinha nos primeiros dias após a aplicação, já os tratamentos T1, T3, T4 não diferiram da testemunha (T5).

Não houve presença de inimigos naturais, bem como, injúrias causadas por algum dos tratamentos.

Os resultados diferem dos obtidos por Sousa (2017), Silva et al (2011) e Alécio (2007). Os extratos utilizados não foram capazes de matar os insetos-pragas, mas tiverem efeito repelente para algumas pragas, sem afeito sobre $C$. arcuatus.

Figura 1: Insetos-praga e injúrias associadas ao feijão-caupi Vigna unguiculata. (A) Vaquinha Cerotoma arcuatus; (B) Percevejo vermelho Crinocerus sanctus; (C) Perfurações no limbo foliar causadas por $C$. arcuatus. Fonte: Própria.

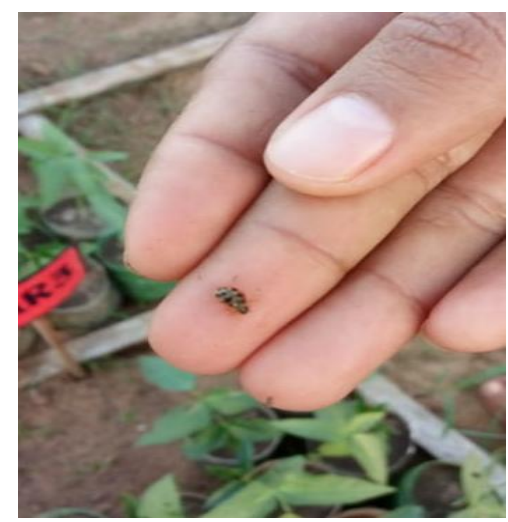

(A)

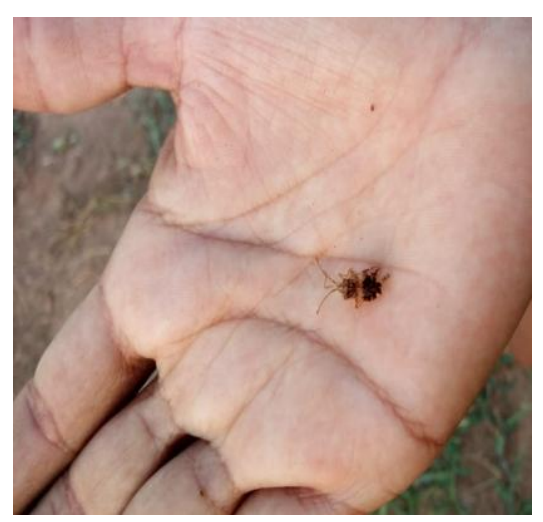

(B)

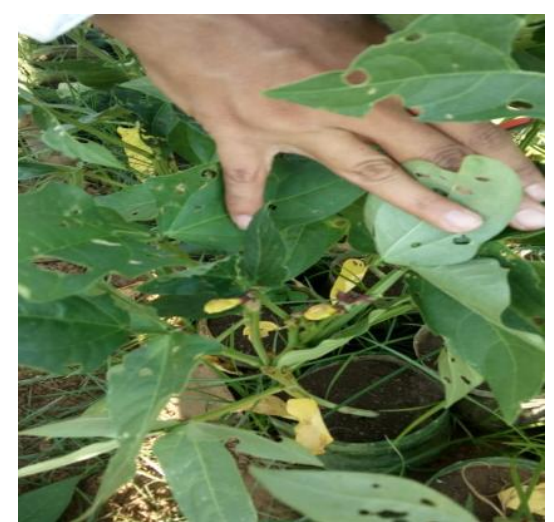

(C)

\section{Conclusões}

Os tratamentos não diferiram da testemunha, por não apresentarem efeito tóxico sobre os insetos-praga.

Embora os tratamentos não tenham apresentado toxicidade sobre esses insetos, houve redução do ataque de percevejo e nenhum ataque de pulgão preto, mosca branca e cigarrinhaverde, pela capacidade de repelir que esses extratos vegetais possuem.

\section{Referências}


ALÉCIO, M. R. Toxicidade do extrato de Derris amazonica Killip a adultos de Cerotoma arcuatus Olivier, 1791 (Coleoptera: Chrysomelidae), Manaus-AM. 2007.

ALMEIDA, A. L. G.; ALCÂNTARA, R. M. C. M.; NÓBREGA, R. S. A.; NÓBREGA, J. C. A.; LEITE, L. F. C.; SILVA, J. A. L. Produtividade do feijão-caupi cv BR 17 Gurguéia inoculado com bactérias diazotróficas simbióticas no Piauí. Rev. Bras. Ciênc. Agrár. Recife, v.5, n.3, p.364-369, 2010.

ANDRADE JÚNIOR, A. S et al. Cultivo do feijão-caupi (Vigna unguiculata (L.) Walp). Teresina: Embrapa Meio-Norte, 2002. (Embrapa Meio-Norte. Sistemas de Produção).

BARROS, M. A.; ROCHA, M. DE M.; GOMES R. L. F.; SILVA K. J. D. E; Avaliação de genótipos de feijão-caupi de porte semiprostrado na região Meio-Norte do Brasil. Pesquisa Agropecuária Brasileira, Teresina- PI. 2011.

EMBRAPA: Empresa Brasileira de Pesquisa Agropecuária Ministério da Agricultura, Pecuária e Abastecimento. Cultivo do Feijão-caupi (Vigna unguiculata (L.) Walp). Teresina - PI, 2011.

FREIRE FILHO, F.R. EMBRAPA: Empresa Brasileira de Pesquisa Agropecuária. FeijãoCaupi no Brasil: produção, melhoramento genético, avanços e desafios. Teresina-PI, 2011.

FREIRE FILHO, F. R.; RIBEIRO, V. Q.; ROCHA, M. M.; SILVA, K. J. D.; NOGUEIRA, M. S. R.; RODRIGUES, E. V. Produção, melhoramento genético e potencialidades do feijão-caupi no Brasil. IV Reunião de Biofortificação, Teresina- PI, 2011.

GALLO, D.; NAKANO, O.; SILVEIRA NETO, S.; CARVALHO, R. P. L.; BATISTA, G. C. DE; BERTI FILHO, E.; PARRA, J. R. P.; ZUCCHI, R. A.; ALVES, S. B.; VENDRAMIN, J. D.; MARCHINI, L. C.; LOPES, J. R. S.; OMOTO, C. 2002. Entomologia Agrícola. Piracicaba: Fealq. 920 pp. (Biblioteca de Ciências Agrárias Luiz de Queiroz, 10).

PONTES, F. S. S. Atividade inseticida de extratos e óleos vegetais sobre ninfas de pulgãopreto-do-feijoeiro (Aphis craccivora Koch). (TCC) Fortaleza-CE, 2005.

SILVA, C. P et al. Extratos Vegetais de Espécies de Plantas do Cerrado SulMatogrossense com Potencial de Bioherbicida e Bioinseticida. UNICIÊNCIAS, v. 21, n. 1, p. 25-34, 2017.

SILVA, D. C. O. et al. Controle de insetos-praga do feijão-caupi na savana de Roraima. Revista Agro@mbiente On-line, v. 5, n. 3, p. 212-219, setembro-dezembro, 2011.

SOUSA, M. A. Controle do pulgão aphis craccivora koch em feijão-caupi com óleos vegetais fixos e essenciais. Dissertação, Teresina-PI, 2017. 
